\title{
Taking the best from real teaching environments
}

\author{
Iolanda Bueno de Camargo Cortelazzo \\ Universidade Tuiuti do Paraná, Rua João Azolin, 435 casa 13, 82015-040 Curitiba, Paraná, \\ Brasil
}

iolanda.cortelazzo@utp.br

Key words: Collaborative Learning, ICT, Learning Environments

\begin{abstract}
This paper offers a description of the scenarios I have faced and the approaches I have used during my teaching experience. In particular I have used ICT to mediate knowledge construction and critical thinking skills development with under-graduate students in different technological environments in a number of private Higher Education institutions. This work has focused on the use of ICT as a collaborative learning and teaching tool. The reactions of students in the institutions have been surprisingly varied and the paper explores these reactions and the outcomes of the use of ICT.
\end{abstract}

\section{INTRODUCTION}

In many countries in Latin America and in other parts of the Western world, several management problems are created for teachers when there are too many students in Higher Education classrooms. Too many can mean up to eighty or ninety students in a single class under the responsibility of a single subject-specific teacher. Teachers understandably find it difficult to manage their classes and carry out cooperative and collaborative learning with their students

Most of the private colleges and some private universities have to deal with the economic difficulties faced by many of their students who belong to lower levels of the society. To maintain their business these institutions run most economically with large classes.

The original version of this chapter was revised: The copyright line was incorrect. This has been corrected. The Erratum to this chapter is available at DOI: 10.1007/978-0-387-35663-1_34 
Educational environments, technologies and human resources vary markedly from institution to institution. Some offer very good working conditions and possibilities of continuing self-development for their staff, as well as creating good learning environments. However, most Higher Education institutions in Latin America employ hourly-paid teachers. Most of these teachers work in many different institutions in order to survive. That is a real concern to course coordinators and college deans because these teachers have neither the time nor the resources to invest in their on-going academic development and research.

I have been working in teacher development and running graduation courses since 1972, but my classes never had more than 30 students until 2000. In 2001, I started teaching under-graduation programmes with classes varying from 40 to 80 students in a single room. Many people say we can not have good quality in such large classes but teachers should try to work in a way that allows students to acquire and construct knowledge as well as skills. If we use ICT in an appropriate way we can develop our students' critical-thinking skills and their creativity.

\section{TEACHING MEDIATED BY ICT - A WORKING SCENARIO}

My main approach is to try and develop work that stimulates student cooperation and collaboration alongside their genuine will to learn (Cortelazzo 2000). Although the institutions where I have taught are private institutions, the students come from low medium classes and have low incomes. Consequently our mission is to ensure they get the most from the payments they make because these payments represent considerable sacrifice for themselves and for their families. They also represent a major investment in what they hope will be a better lifestyle.

Institution A has an up-to-date technological environment. There are three networked laboratories and every class is connected to the NT Windows-based network and to the Internet. Every student has an e-mail address and, through the college networking system, students have on-line access to the institution's facilities. Teachers can use the mimeo system, have all the class work prepared in advance and uploaded to appropriate folders at the college and save their electronic board class-work in their own folders.

Although the students soon mastered the operation of the system and used the network to communicate and do research, it was necessary to develop and implement a two-year programme to help most of the teachers use the ICT environment. Even so, their main use of the technological environment has been to respond to the administrative demands of the 
courses. Only a few use it pedagogically. As the pedagogical coordinators have realized this situation, they have offered some pedagogical workshops not only to stimulate teachers but also to offer them guidelines and suggestions to help them introduce ITC into their daily teaching routine.

Institution $\mathrm{B}$ is a traditional institution trying to choose the best technological solution for its specific needs. In the classrooms, on the campus I work at, we only have whiteboards and pens. If we want, or need, to use TV, video, overhead projector or the single forty-place stand-alonecomputer laboratory, we need to assign our requirements a week in advance. Only the Course Coordinator's computer and three computers in the library have Internet access. About $30 \%$ of the students have free web-mail access or a paid Internet account of their own. Most of the teachers do not use Internet facilities, they simply use computers as typing machines and the ICT they are used to are books, chalk and boards. Few use video and television to support their class-work. Only very few access the Internet either for communication or for research. In fact, most of them do not carry out research. Consequently, their students are on a similar path. Many of the students have already been involved in teaching and their acquaintance with ICT is as narrow as that of their teachers. This situation does not seem to change even if the mastery and use of ICT is modelled to them at Teacher College throughout the subject-specific course ITC in Education.

In August 2001 I started working in another institution - institution C - a university with over forty different teaching courses. I have been teaching both on the Graduate Programme in Education and on the under-graduate programme at the Teacher College. The technological environment is more sophisticated and there is more technology available than at B. It is, however, poorer than at $\mathrm{A}$.

There are many laboratories and all the teachers and students have an email address (although many do not know they have it). Most of the teachers neither use computers as teaching tools nor access Internet as users - they just access it because they have to register the students' grades via the Internet. On the other hand this institution has a dynamic web site. Most of the news or information to teachers and students is delivered by e-mail or communicated on their homepage. They have an Intranet available for teachers and students. They also have a Department for Teacher Development that offers some workshops and lectures.

My research in this university is related to the use that former students of Pedagogy (who graduated from 1998 to 2001) make of ICT in their current employment. This research has generated information to help support my own teaching, general ICT teaching and the use of ICT in the Teacher College programmes. 


\section{TEACHING MEDIATED BY ICT - AN APPROACH TO TECHNOLOGY MEDIATING TEACHING AND LEARNING}

I taught New Technologies and Education, the Multimedia Laboratory and Distance Education in the Teacher College (Institution A) and History of Computing and Technology and Society in the Computing Science Course at Institution B from February to June 2001. Since August 2001 I have been teaching ICT applied to Education at Institution C. Although the subjects are different, they have in common the objective of making students think about ICT and their application in their specific professional area.

Teaching these different subjects allows me to experience different points of views from technophiles to people who do not wish to work with machines - not only students, but also teachers and researchers.

Students are required to think about the concepts of education (teaching and learning as two sides of the same coin), communication and technology. Extensive class discussion helps students to consider and clarify their understanding of these concepts.

Teacher and students come to a common understanding of the work of the course. ICT is defined as any way that generates, stores, processes, distributes and reproduces information applied to solve any problem or create better life conditions. Paper, files, magnetic tapes and optical discs are means of storing information. Xerox machines, overhead projectors, slide projectors and data displays are means of reproducing information. Computers and robots are means of processing information. Fax, telephone, newspaper, magazines, mail, television, telex and computer networks (e.g. the Internet) are means of distributing information. On the other hand, students suggested that we, the teachers, are the first known effective 'ICT' at school, as we generate, store, process, distribute and reproduce not only information but knowledge with our students.

The idea of collaboration is also clarified. Collaboration is the basis for a consistent and productive partnership and both are essential to the completion of a project where joint construction is expected. In school education collaboration is also fundamental and must be present among students and between teacher and students. The next step with students is to state what collaboration is and clarify the its rules. Every student must make a meaningful contribution to the project according to his/her competence. Everyone has long-term objectives which must be inter-related to the collective objectives of their group. All participants need to bring their own values, skills and competence to contribute to an effectively functioning project. Fundamentally everyone must know exactly what their role and responsibilities are, what these limits allow, and the benefits or prejudices 
inherent to these functions and responsibilities. It is not necessary for everybody to be friendly but it is important they respect each other and work for the development of the group. It is also important to consider counter arguments, respect each other's thoughts, incorporate them when necessary and recognize that one's own convictions are not appropriate at that moment. Information must be shared, discussed, analyzed and processed by the whole group to transform it into enriching knowledge. From divergence and argumentation in a conscious dialectic may result rich and meaningful products for each of the group participants. Once the participants build up wide connections, develop interconnected work forms and share information as well as specific knowledge, they become teachers and students of each other.

Communication between partners is essential in collaborative projects. It can happen in different ways and need not necessarily be verbal but it must be continuous. Personal constructions may be enriched with other contributions, integration occurs, the interdependence is maintained and the process is always receiving feedback. Students are required to build up a 'sharing space' as a real test for collaborative action. ICT are necessary in this collaborative project since they allow teacher and students to develop mutual collaborations even if they are far apart. Telephone, fax and mail services like regular mail or Federal Express have being used for a long time. Electronic networks have expanded the possibilities creating a meaningful cyberspace characterised by collaboration.

Students are required to examine and consider these rules and reflect on the importance that socially shared knowledge holds for learning. Interactive collaborations may contribute to the shared knowledge construction and inter-subjectivity development (known as the capacity to have friendship and emotion with others). They set a shared reference regarding objects and external circumstances (Crook 1996).

Thus, in each course new collectives are formed, they collaborate mutually and construct new knowledge, aggregating value to the existing knowledge, weaving new relationship webs and new relations between different subjects, consolidating a collective, cooperative and collaborative intelligence.

All the courses have specific objectives and the approaches to each one are inevitably different but the position as regards knowledge acquisition and construction must be the same. Teacher College students will deal with learners (pupils) in educational environments, and Computing Science students will deal with learners (users, consumers, clients) in real world environments. All will be required to be competent, efficacious and effective in their field. They will have to know how to make decisions, provide solutions and be creative in their specific professional action. Therefore they 
have to be developed and trained to be able to make up their mind at the right moment, to provide the best solution, to be creative and also to be cooperative and collaborative. That is why they have to learn how ICT may or may not mediate their actions and preview possible problems and/or dangers these technologies may bring. They have to experience ICT as collaborative tools which can enhance their actions and promote their development as human beings. They have to reflect on their use of ICT and on the positive and negative consequences of its use.

The reactions I have experienced to the use of ICT in the three institutions have been surprisingly different. These experiences demand reflection from teacher trainers and College Coordinators.

The Scientific Computing students were more ready to study and work with ICT and to think about their use and their role than the Teacher College students. Many of the latter have already been working as teachers or trainees in elementary schools or kindergarten. They are resistant to innovation. They enjoy being involved in practical, hands-on work but do not like to write or read. Many are there just to get a certificate.

In all the three institutions students were required to read extensively. They were guided to summarise and make reviews of their writing. Writing in ink and on the computer, drawing with crayons, drawing on the computer, photographing, scanning photos and inserting them in MSWord texts were some of the required activities. Although the subject programme in the less technological Institute required computer activities - the computer laboratory was available only once a month. Students were stimulated to use other ICT.

They created projects preparing radio programmes recorded in audio; they videotaped activities and presented them on television, they prepared slides with presentation software and showed them to their peers as overhead projector transparencies.

Although the change in their behaviour and their beliefs was a slow process, it is encouraging to see it happen. Some times students are not aware they have changed - sometimes their attitudes and posture change a little faster than their consciousness of it.

It was hard work, but they started to realize how important it is to experience ICT, discuss its use, discover their unique uses and integrate them in Education. They have also realized that ICT will not change education nor solve the problem of quality in teaching. Bad teaching may become worse if ICT is introduced inappropriately.

The students I currently work with enrolled in June 2001 and started the Pedagogy course in August. There are 50 students and we should go to the computer laboratory for every class. However, we go twice a month because they are first required to read about technology and education, collaborative work and team work and then they are involved in class discussions. Finally 
they go to laboratory where they perform tasks, conduct research, write about their findings, create presentations and communicate with their peers and other teachers from different universities in other cities. They write a lot more, they discuss much more and they like what they do because they know that their work is not going to lie forgotten in a drawer. It may be published on the school bulletin board or on the WWW. As they can read their colleagues' or other students' work - theirs will be read too.

\section{TEACHING MEDIATED BY ICT - OUTCOMES}

When these students use the word processor, they write much more and with fewer grammatical mistakes. They are asked to follow three steps which are very difficult to follow when you write with pencil or ink - create, revise and edit. They do this collaboratively and enjoy it. Some are not enthusiastic about computers but are stimulated to use other technology.

Students from the three institutions are communicating with each other on the Internet. As they study different subjects, live in different communities and belong to different cultures, they have different points of view. These can enrich their exchanges. They discuss not only the use of ICT in education but also how they can help to improve humanity and be involved in the fight for peace in the world. Their participation in electronic forums increases as they realise their doubts, concerns, questions and comments are read and considered by many other people besides their teachers.

All students were required to finish the school year in June 2002 with some communication products produced and reflected upon during their course. These should include articles, photographs, audio and videotapes, digital texts and personal home-pages designed and created by themselves, individually and in work teams. These will be used in education and in their everyday life.

They have gradually realized that ICT offers an interesting media for them to promote good quality education, respect and solidarity, through individual and collective collaborative projects. They have learnt that communication and collaboration are the key to help change society, to enhance human relations and to make the world a better place in which to live.

Teachers and students are part of a cyberspace where different attitudes, beliefs and thoughts contribute to create a new scenario for a more meaningful and peaceful future for humanity.

ICT helps teachers at university, teacher trainers and human resource managers to work with different knowledge, different competencies and 
different skills. They help them to integrate both cognition and emotion to produce the best teachers and students and, above all, the best human beings.

Teachers cannot change attitudes, behaviours and beliefs in a short time. However, it is very rewarding to see students becoming involved in the projects and working together collaboratively. It is also impressive to realize how much teachers learn from them and how much we change and grow as professionals and human beings.

\section{REFERENCES}

Cortelazzo, I. (2000) Collaboration, Teamwork and the Technologies of Communication:

Relationships of Nearness in Graduation Courses, Doctoral thesis, Faculdade de Educação da Universidade de São Paulo, Brasil.

Crook, C. (1996) Computers and the Collaborative Experience of Learning, Routledge, New York. 